NASA TECHNICAL NOTE

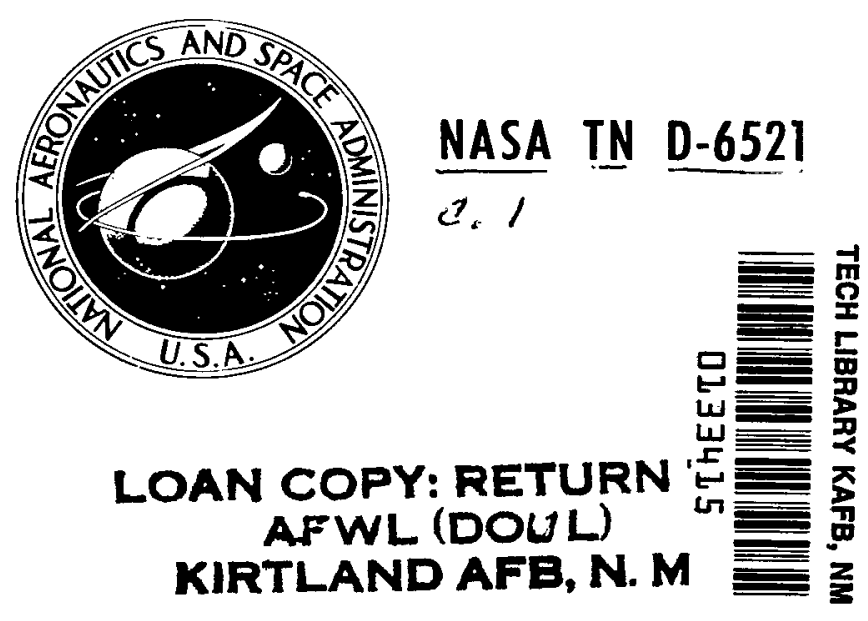

ION AND LASER MICROPROBES

APPLIED TO THE MEASUREMENT

OF CORROSION-PRODUCED HYDROGEN

ON A MICROSCOPIC SCALE

by Hugh R. Gray

Lewis Research Center

Cleveland, Obio 44135

NATIONAL AERONAUTICS AND SPACE ADMINISTRATION - WASHINGTON, D. C. - DECEMBER 1971 
4. Title and Subtitle ION AND LASER MICROPROBES APPLIED TO THE MEASUREMENT OF CORROSION-PRODUCED HYDROGEN ON A MICROSCOPIC SCALE

7. Author(s)

Hugh R. Gray E-6546

9. Performing Organization Name and Address 10. Work Unit No.

Lewis Research Center

National Aeronautics and Space Administration Cleveland, Ohio 44135

12. Sponsoring Agency Name and Address

National Aeronautics and Space Administration Washington, D. C. 20546 $134-03$

11. Contract or Grant No.

13. Type of Report and Period Covered Technical Note

14. Sponsoring Agency Code

15. Supplementary Notes

16. Abstract

An ion microprobe and a laser microprobe were used for the first time to measure concentrations of corrosion-produced hydrogen on a microscopic scale. Hydrogen concentrations of several thousand ppm were measured by both analytical techniques below the fracture surfaces of hot-salt stress-corroded titanium alloy specimens. This segregation of hydrogen below fracture surfaces supports a previously proposed theory that corrosion-produced hydrogen is responsible for hot-salt stress-corrosion embrittlement and cracking of titanium alloys. These advanced analytical techniques suggest great potential for many areas of stress-corrosion and hydrogen embrittlement research, quality control, and field inspection applications.

17. Key Words (Suggested by Author(s))

Ion microprobe; Laser microprobe; Hydrogen determination; Microanalytical techniques; Hotsalt stress-corrosion; Titanium alloys; Hydrogen embrittlement

19. Security Classif. (of this report) Unclassified
20. Security Classif. (of this page) Unclassified
18. Distribution Statement

Unclassified - unlimited

\footnotetext{
* For sale by the National Technical Information Service, Springfield, Virginia 22151
} 


\title{
ION AND LASER MICROPROBES APPLIED TO THE MEASUREMENT OF CORROSION-PRODUCED HYDROGEN ON A MICROSCOPIC SCALE
}

\author{
by Hugh R. Gray
}

Lewis Research Center

\section{SUMMARY}

An ion microprobe and a laser microprobe were used for the first time to measure concentrations of corrosion-produced hydrogen on a microscopic scale. Hydrogen concentrations of several thousand ppm were measured by both analytical techniques below corroded and fracture surfaces of hot-salt stress-corroded titanium alloy specimens. This extremely high concentration compares with only about 100 ppm hydrogen determined by standard vacuum fusion chemical analyses of bulk samples. Both the ion and laser microprobes were used to measure hydrogen concentration profiles in stepped intervals to substantial depths below the original corroded and fracture surfaces. For the ion microprobe, the area of local analysis was 22 micrometers in diameter; for the laser microprobe, the area of local analysis was about 300 micrometers in diameter.

The segregation of hydrogen below fracture surfaces supports a previously proposed theory that corrosion-produced hydrogen is responsible for hot-salt stresscorrosion embrittlement and cracking of titanium alloys.

These advanced analytical techniques suggest great potential for many areas of stress-corrosion and hydrogen embrittlement research, quality control, and field inspection of corrosion problems. For example, it appears possible that a contour map of hydrogen distribution at notch roots and crack tips could be quantitatively determined. Such information would be useful in substantiating current theories of stress-corrosion and hydrogen embrittlement.

\section{INTRODUCTION}

Corrosion-produced hydrogen has long been suspected as the embrittling species in many stress-corrosion systems. Hydrogen is known to be the embrittling species generated during the electroplating of high strength steels (refs. 1 and 2). One theory 
suggests that hydrogen diffuses to and segregates near crack tips and notch roots (ref. 3). However, until recently, there had been no quantitative, analytical techniques capable of determining hydrogen concentrations on a microscopic scale.

The only quantitative method used in the past for hydrogen determinations is the familiar hot extraction or vacuum fusion followed by conventional methods of gas anaIysis. However, this method yields only the total or average hydrogen content of the bulk sample submitted for analysis. Several new, microanalytical techniques have been developed in recent years. These include autoradiography (refs. 4 and 5), neutron radiography (refs. 6 and 7), lithium isotope microprobe (ref. 8), and neodymium hydride reaction (ref. 9). All these tech :ques are qualitative and are confined to surface analyses only. They also require special safety procedures and equipment not readily available in most materials laboratories.

This report describes the results obtained by two advanced analytical techniques that have the capability of quantitatively determining complete contour maps of hydrogen concentration to substantial depths below the original corroded and fracture surfaces. Both the ion and laser microprobes were used to determine hydrogen concentration profiles in titanium alloy specimens that had been subjected to hot-salt stress-corrosion exposures. The results obtained were used to evaluate a previously proposed (refs. 10 and 11) theory that hydrogen is the embrittling species in the process of hot-salt stress-corrosion of titanium alloys.

\section{MATERIAL AND SPECIMENS}

\section{Material}

A titanium - 8-percent-aluminum - 1-percent-molybdenum - 1-percent-vanadium (Ti-8Al-1Mo-1V) alloy was used throughout this investigation. The alloy was a 2.5centimeter (1-in.) diameter bar stock in the mill-annealed condition $\left(790^{\circ} \mathrm{C}\left(1450^{\circ} \mathrm{F}\right)\right.$ for $1 \mathrm{hr}$, air cooled). The chemical analysis and mechanical properties have been reported previously (refs. 10 to 12 ). The vendor's reported hydrogen concentration (70 ppm) had previously been confirmed by numerous vacuum fusion chemical analyses to be $70 \pm 15 \mathrm{ppm}$ (ref. 11). One 5000-micrometer (0.2-in.) thick wafer was cut from the bar stock with an oil-cooled power hacksaw. This sample was then used as the standard for all subsequent ion and laser microprobe analyses.

\section{Sp?cimens}

Tubular specimens of the type illustrated in figure 1 were used in this investigation. These specimens have been used in previous investigations (refs. 10 to 12) for studying 


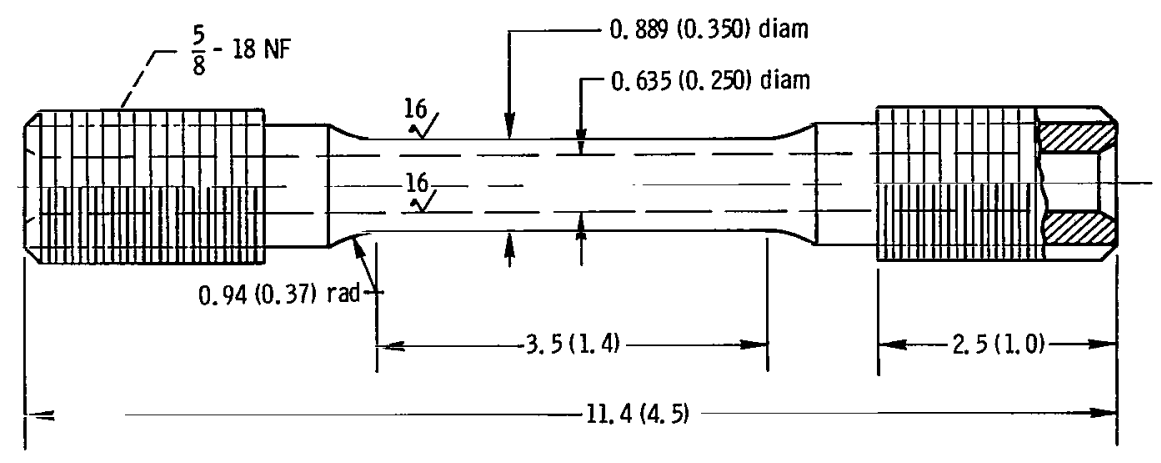

Figure 1. - Tubular, titanium alloy specimen used in this investigation. (All dimensions are in $\mathrm{cm}$ (in.)).

the hot-salt stress-corrosion characteristics of titanium alloys in a simulated turbineengine compressor environment. The specimens were machined from as-received bar stock. They received no subsequent treatments other than cleaning with acetone and distilled water immediately before being hydrogenated or coated with salt.

Hydrogenated specimen. - One specimen was thermally hydrogenated at $650^{\circ} \mathrm{C}$ $\left(1200^{\circ} \mathrm{F}\right)$ for 30 minutes at a gas pressure of about 0.12 meganewton per square meter (17 psia). The furnace was flushed with argon, and the specimen was cooled to room temperature within 1 hour. Vacuum fusion chemical analyses revealed that this hydrogenating treatment resulted in the absorption of $3800 \mathrm{ppm}$ of hydrogen in the specimen (ref. 10).

Creep-exposed specimen. - Another specimen was coated with 0.03 milligram per square centimeter $\left(0.2 \mathrm{mg} / \mathrm{in} .{ }^{2}\right.$ ) of salt in a dynamic air facility described previously (ref. 12). The salted specimen was then exposed at $430^{\circ} \mathrm{C}\left(800^{\circ} \mathrm{F}\right)$ in a static-air creep furnace for 115 hours at 350 meganewtons per square meter $(50 \mathrm{ksi})$. After this stresscorrosion exposure, the specimen was tensile tested at room temperature at a constant crosshead speed of $1.3 \times 10^{-2}$ centimeter per minute $\left(5 \times 10^{-3} \mathrm{in} . / \mathrm{min}\right)$ to determine residual ductility. Based on measurements of the outside diameter of the tubular specimen, the apparent reduction of area was 12 percent, and the elongation was 10 percent. These values indicate that the specimen had been severely embrittled as a result of the stress-corrosion exposure. (Before creep-exposure, specimens had an apparent reduction of area of 33 percent and an elongation of 18 percent.) However, metallographic examination did not reveal any evidence of stress-corrosion cracks in the exposed specimen. Small samples $(0.1 \mathrm{~g})$ cut from regions immediately adjacent to the fracture surface of the broken pieces of the specimen were analyzed by vacuum fusion. Previous analyses indicated that the average bulk-hydrogen concentration of these samples was 90 to $126 \mathrm{ppm}$ (ref. 10 ). 
Stress-rupture specimen. - Another specimen was coated with 0.1 milligram per square centimeter $\left(0.6 \mathrm{mg} / \mathrm{in} .{ }^{2}\right)$ of salt and then exposed in static air at $430^{\circ} \mathrm{C}\left(800^{\circ} \mathrm{F}\right)$ at 550 meganewtons per square meter ( $80 \mathrm{ksi})$. The specimen ruptured after 505 hours with an apparent reduction of area of only 14 percent and an elongation of 10 percent. (These properties compare with an unsalted specimen rupture life of about $1500 \mathrm{hr}$, 50-percent apparent reduction of area and 36-percent elongation (ref. 10).) Stresscorrosion cracking was extensive along the bore of the specimen. That the cracking had occurred during stress-corrosion exposure was revealed by a continuous ring of corroded material about 400 micrometers (0.016 in.) deep on the fracture surface next to the salted bore of the specimen. A previous vacuum fusion analysis indicated that the average bulk-hydrogen concentration of this specimen was $111 \mathrm{ppm}$ (ref. 10).

\section{EXPERIMENTAL PROCEDURE}

\section{Ion Microprobe}

Principle of the technique. - These analyses were performed at the GCA Corp., GCA Technology Division, Bedford, Massachusetts, by F. G. Satkiewicz under contract to NASA. The technique has been called an ion- robe mass spectrometer (refs. 13 and 14), an ion solids surface analyzer (ref. 15), an ion microanalyzer (ref. 16), and an ion microprobe mass analyzer (refs. 17 and 18). The instrument used in this investigation is just one of the three commercially available instruments that have varying degrees of sophistication and optional features.

A typical system consists of an evacuated sample chamber, a specimen manipulator, an ion gun for producing a primary beam of positively charged ions (argon or oxygen), a double-focusing mass spectrometer with stigmatic imaging, an ion detector, a photomultiplier, an x-y recorder, and/or a viewing screen and camera (see fig. 2).

The primary ions are accelerated at a voltage of 1 to 20 kilovolts and strike the sample at a preselected site. The beam diameter can be focused from about 6000 down to 200 micrometers. The primary ion beam continuously sputters and erodes away the surface of the sample. The sputter-erosion linear depth rate ranges from several atom layers to several micrometers per minute for the defocused $(6000 \mu \mathrm{m})$ and focused $(200 \mu \mathrm{m})$ beams, respectively. Since the primary ions have a much greater energy than the bonding energies of atoms in the sample, the impinging ions eject material or secondary ions from the sample. The positive secondary ions from the sample are collimated perpendicularly from the sputter-erosion crater before entering the mass spectrometer for analysis. 


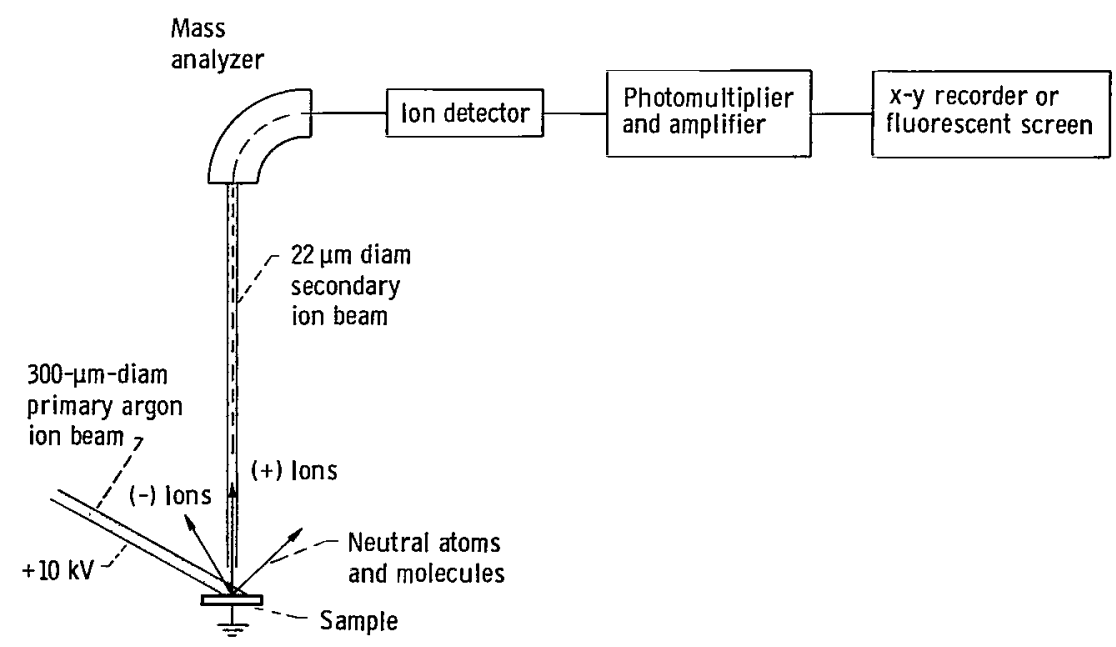

Figure 2. - Ion microprobe system.

A variable-energy window can be used to exclude all polyatomic ions from the mass spectrum since their energy is less than that of the monatomic ions. The collimated ions are separated by the mass spectrometer by mass-charge ratio. The ions strike an alumina target and electrons are released. A multiplied electron image can be detected on a fluorescent screen or by a recording system. Entire mass spectrums can be obtained by recording ion current while scanning the desired portion of the atomic mass range. The mass spectrometer may be fixed on a single element and a concentration profile can be determined as a function of sputter-erosion time or depth below the original surface. Because of the high vacuum $\left(10 \mu \mathrm{N} / \mathrm{m}^{2}\left(10^{-7}\right.\right.$ torr $\left.)\right)$ and because of the collimation and capture of only positive ions, the spectrum is not complicated by gas phase reactions. Thus, ions that are detected by the mass spectrometer indicate only species that are actually on or in the sample.

Mode of operation. - The specific experimental procedure used in this investigation was as follows. The surface analyzed on the as-received titanium alloy standard had been cut with an oil-cooled, power hacksaw. The surface analyzed on the thermally hydrogenated sample was the outer diameter of the tubular specimen which had been machined before hydrogenation. The surfaces analyzed on the creep-exposed and stressrupture specimens were both the salt-corroded bore and the fracture surface. Although these surfaces had been exposed to distilled water when the concentration of the salt coating was measured, the surfaces were not cleaned or prepared in any other manner. All the specimens had been stored for up to 2 years between stress-corrosion exposure and the subsequent microprobe analyses. All samples were mounted on massive chill blocks to minimize beam heating effects. 
The analysis sites were positioned by means of a calibrated specimen stage and a low-power, optical viewing system. The primary beam of argon ions was accelerated at a potential of 10 kilovolts with a focused beam diameter of about 200 micrometers. A sputter-erosiun rate of 3.7 micrometers per minute was used. An energy window of 250 electron volts and a beam collimation of 22 micrometers were used for the secondary ions. The mass spectrometer was calibrated by determining the intensity ratio of titanium to hydrogen in the as-received titanium alloy standard. The limit of detection was estimated to be less than $1 \mathrm{ppm}$ hydrogen in the alloy. The mass spectrometer was then set only for hydrogen. The intensity of the hydrogen peak was recorded as a function of sputtering time, thus generating a concentration against depth profile. The mode of operation and typical data determined are schematically illustrated in figure 3.

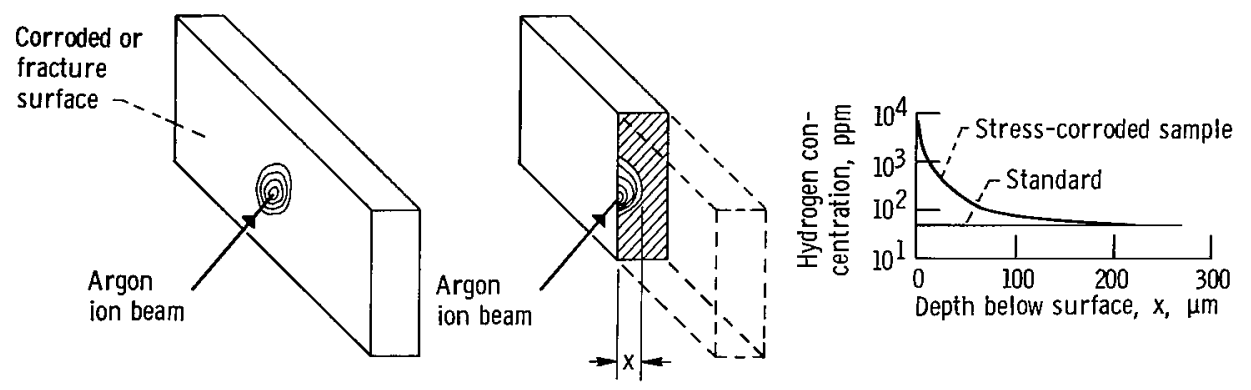

Figure 3. - Schematic represen.ation of ion microprobe technique.

\section{Laser Microprobe}

Principle of the technique. - The laser-beam hydrogen detector (laser microprobe) was developed by the Boeing Co., Aerospace Group, Seattle, Washington. These analyses were performed by $\mathrm{K}$. B. Das under contract to NASA. There is no information about this technique available in the literature. The system essentially consists of an evacuated specimen chamber, a high power, continuous wave laser, an electrolysis cell, a semipermeable membrane (SPM), a vacuum-ion pump, and a tank of high purity argon gas. The system is illustrated in figure 4. Hydrogen is released from the sample by heating a small volume, the heat affected zone (HAZ), with the laser beam. The liberated hydrogen is directed toward the SPM by the flowing argon carrier gas. The SPM lets only hydrogen diffuse through it while remaining impermeable to other gases. On the other side of the SPM is a continuously pumped high vacuum chamber. The pressure in this chamber is monitored by measuring the current through the vacuum-ion pump. Once the chamber is evacuated to its base vacuum of 0.1 micronewton per square meter ( $10^{-9}$ torr), any permeation of hydrogen through the SPM will result in an increase in the ion current. This is related to the amount of hydrogen in the carrier gas stream by means of a calibration curve. Thus, after the detector is calibrated by generating 


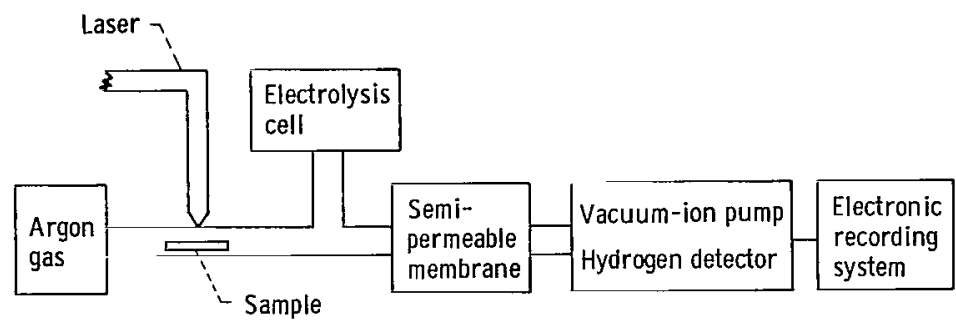

Figure 4. - Laser microprobe system.

known amounts of hydrogen by electrolysis, the amount of hydrogen in the gas stream liberated from the sample can be calculated.

Mode of operation. - The samples used for the laser microprobe analyses were portions of the same samples used for the ion microprobe analyses. The cross sections of all samples analyzed by the laser microprobe technique were cut by the vendor with a hacksaw in dry air. All samples were then mounted on a heavy copper chill block to provide a heat sink.

The analysis sites were positioned by means of a calibrated specimen stage. How ever, there was no optical system for confirming the position of the initial analysis site. The argon carrier gas flow rate was 32 cubic centimeters per minute, and the SPM was heated to about $650^{\circ} \mathrm{C}\left(1200^{\circ} \mathrm{F}\right)$ to enhance the rate of hydrogen diffusion through it. The limit of detection of the analytical system was determined to be $0.4 \mathrm{ppm}$ hydrogen in the gas stream. The diameter of the focused laser beam was 300 micrometers. The beam power was 30 watts, and the exposure time varied from 10 to 30 seconds according to the mass and hydrogen content of the bulk sample. The microsample size (HAZ) was verified by metallographic examination. For an alloy density of 4.5 grams per cubic centimeter, the calculated mass of the HAZ was 10 micrograms.

The mode of operation is illustrated in figure 5. The position of each analysis site was located by both $\mathrm{x}$ and $\mathrm{y}$ coordinates. With the exception of one analytical traverse,

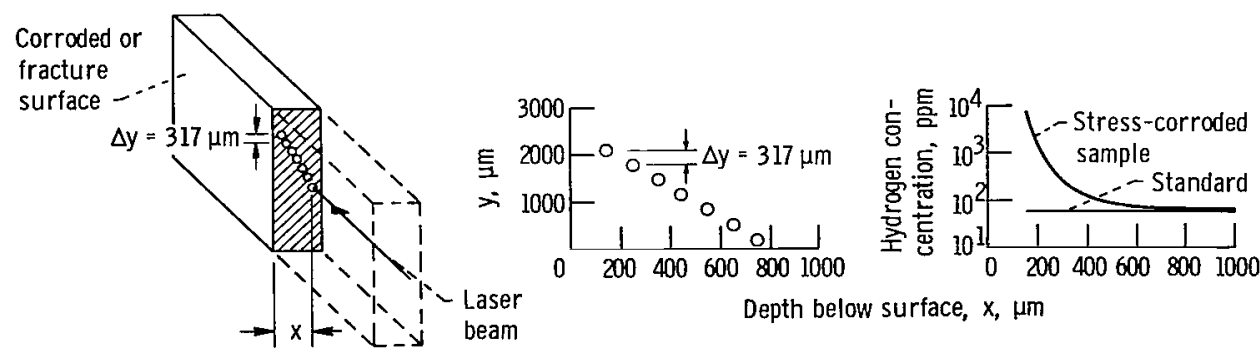

Figure 5. - Schematic representation of laser microprobe technique. 
the distances between analysis sites were constant increments of 317 micrometers along the $y$ coordinate. Hence, only the $x$ coordinates were used to plot the concentration profiles, as shown in figure 5 .

\section{RESULTS AND DISCUSSION}

\section{Ion Microprobe}

Standards. - In order to determine the characteristics and accuracy of this technique, three standard samples were analyzed. Two of the standards were taken from the wafer of bar stock described in the Material section. These samples (70 ppm $\mathrm{H}$ ) served as the basic standard from which all hydrogen concentrations were calculated. The third standard was taken from a longitudinal section of a tubular specimen that had been thermally hydrogenated (3800 ppm H) (ref. 10).

The hydrogen concentration profiles of these three samples are presented in figure 6. The hydrogen concentrations of the profiles for the as-received standards ranged
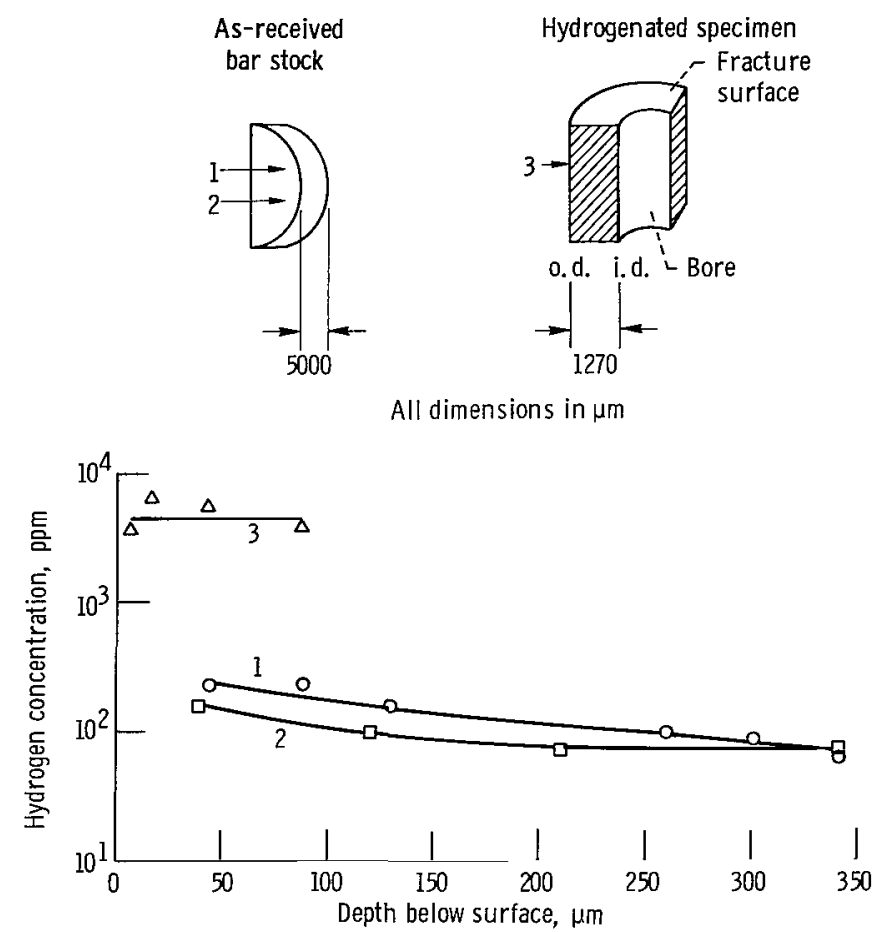

Figure 6. - Ion microprobe hydrogen concentration profiles for asreceived standard $(70 \mathrm{ppm} \mathrm{H})$ and thermally hydrogenated specimen $(3800 \mathrm{ppm} \mathrm{H})$. (The locations of the profiles are indicated by the numbered arrows in the sketches). 
from 170 to $70 \mathrm{ppm}$ and from 240 to $69 \mathrm{ppm}$. These profiles exhibited good reproducibility even though the analyses were made several months apart. However, the relatively high hydrogen concentrations of 170 and $240 \mathrm{ppm}$ determined in the initial $100 \mathrm{mi}-$ crometers below the surface are difficult to rationalize. Perhaps surface heating occurred during the cutting of the samples from the bar stock and resulted in a nonuniform hydrogen distribution. Oxidation of the freshly cut surface in a moist atmosphere may also have contributed to the observed gradient.

The hydrogen profile for the thermally hydrogenated sample agreed well with the bulk analysis determined by vacuum fusion chemical techniques ( $3800 \mathrm{ppm} \mathrm{H})$. The measured concentrations of hydrogen ranged from 3600 to $6100 \mathrm{ppm}$ over a depth of 86 micrometers.

Creep-exposed specimen. - Hydrogen concentration profiles were determined on a specimen that had been creep-exposed for 115 hours at $430^{\circ} \mathrm{C}\left(800^{\circ} \mathrm{F}\right)$ and $350 \mathrm{mega-}$ newtons per square meter $(50 \mathrm{ksi})$ and then tensile tested. These exposure conditions did not result in the initiation of any stress-corrosion cracks in this specimen. Vacuum fusion chemical analyses had indicated that the average bulk-hydrogen content was 90 to $126 \mathrm{ppm}$ (ref. 10). The ion microprobe traverses are illustrated in figure 7. Three transverse profiles $(1,2$, and 3 ) and two longitudinal profiles (4 and 5) were made on a sample cut from the creep-exposed specimen. High concentrations of hydrogen were

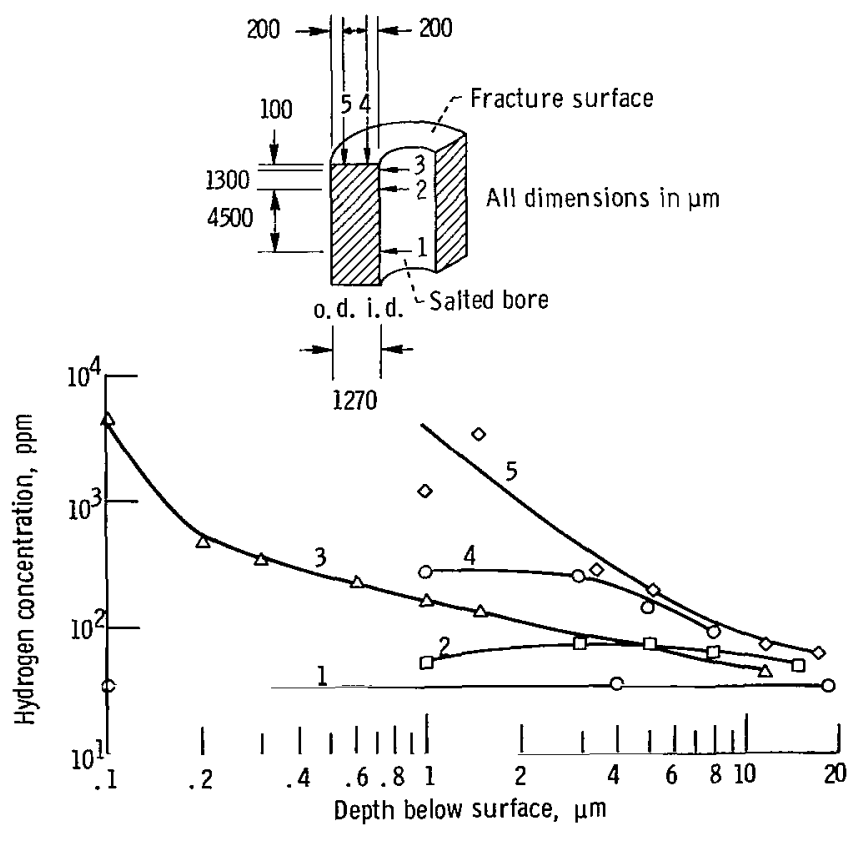

Figure 7. - Ion microprobe hydrogen concentration profiles for creep-exposed specimen. (The locations of the profiles are indicated by the numbered arrows in the sketches. 
measured near the fracture surface. Profile 3, which was measured closer to the fracture surface than profiles 1 or 2 , revealed about $4500 \mathrm{ppm}$ of hydrogen at a depth of 0.1 micrometer. The hydrogen concentration of this profile gradually diminished to the base level of $70 \mathrm{ppm}$ at a depth of about 10 micrometers. Both profiles 1 and 2 were close to the base level hydrogen content. Both of the longitudinal profiles (4 and 5 ) indicated substantial hydrogen contents between depths of 1 to 10 micrometers below the fracture surface. Profile 5 even indicated several thousand ppm of hydrogen at depths of 1 to 2 micrometers below the fracture surface in a region close to the outer diameter of the specimen. Had profiles 4 and 5 been initiated at depths of less than 1 micrometer below the fracture surface, it is possible that even higher hydrogen contents would have been measured. There were no significant deviations from base-level hydrogen content for any of these five profiles between depths of 20 to 260 micrometers. Hence, these data are not represented in figure 7.

Stress-rupture specimen. - A severely cracked stress-rupture specimen was also selected for analysis. This specimen had failed after 505 hours at $430^{\circ} \mathrm{C}\left(800^{\circ} \mathrm{F}\right)$ and 550 meganewtons per square meter $(80 \mathrm{ksi})$. Vacuum fusion tests had indicated that the average bulk hydrogen content was $111 \mathrm{ppm}$ (ref. 10). Both the sample and the regions of analysis were similar to those discussed in connection with figure 7 , and the hydrogen concentration profiles are shown in figure 8 . Once again, for the three transverse profiles (1, 2, and 3) made along the bore of the salt-coated specimen, the hydrogen

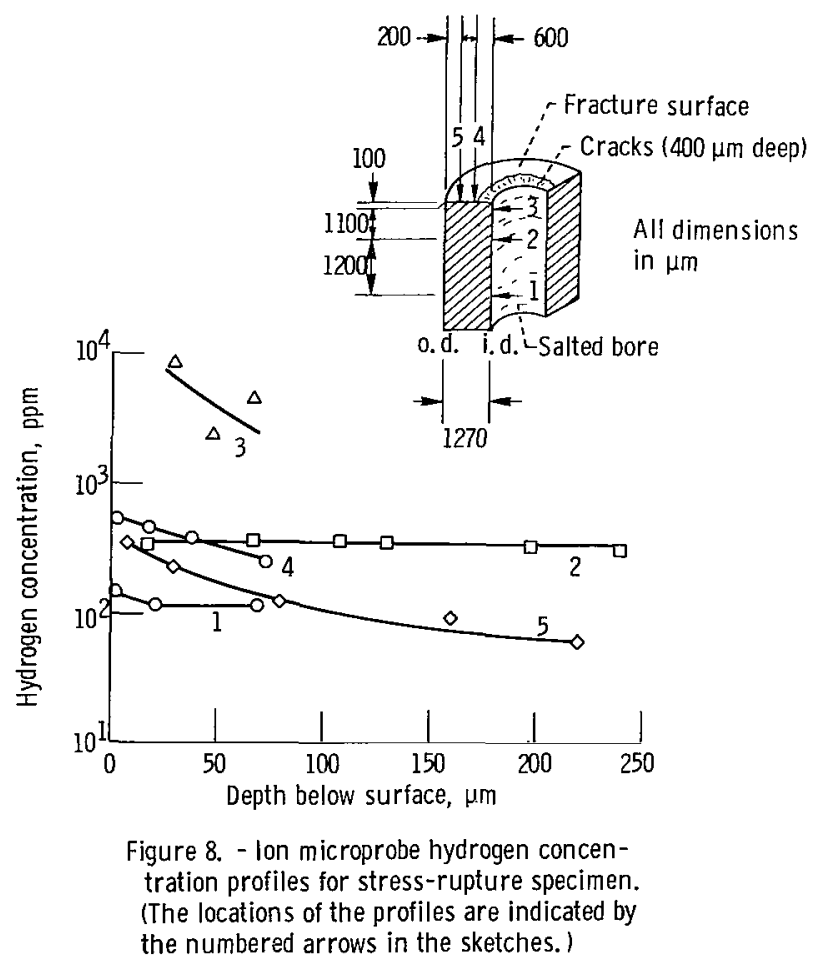


content increased substantially as the fracture surface was approached. Several thousand ppm were measured at various depths along profile 3; only a few hundred ppm were measured along profiles 1 and 2. The two longitudinal profiles ( 4 and 5) indicated decreasing hydrogen concentrations as the analyses were made at increasing depths below the fracture surface, which was also true for the longitudinal profiles measured on the creep-exposed specimen (fig. 7).

Metallographic examination. - Several of the sputter-erosion craters resulting from the ion microprobe analysis were examined by scanning electron microscopy. Micrographs of the sputter-erosion crater of profile 2 of the stress-rupture specimen (fig. 8) are shown in figure 9 . This crater was one of the deepest analyzed in this investigation. Its reported depth of 240 micrometers was based on a sputter-erosion rate of $3.7 \mathrm{mi}-$ crometers per minute for 65 minutes. That the diameter of the crater increased from about 300 to almost 1000 micrometers is of little consequence since the analyzed secondary ions are collimated to a diameter of 22 micrometers from the center of the crater and normal to the specimen surface. However, it is also immediately obvious that the crater is not a smooth, symmetrical Gaussian crater. It is asymmetrical with spikes oriented parallel to the primary ion beam. Similar spikes have been reported previously (ref. 19). They may be due to either electronic interactions within the impinging beam of argon ions or to the microstructure of the titanium alloy, which consists of two phases with different compositions and hardnesses. Examination of this crater indicated that its true depth was about 50 percent less than the calculated depth. Examination of several shallower craters indicated that errors in depth increased from about 10 percent up to a maximum of about 50 percent as the calculated depth increased from 10 to 240 micrometers, respectively.

No corrections have been made in the data presented in this report for these errors observed in the depth of the sputter-erosion craters. In addition, the effect of the spikes within the craters is unknown, but this does not appear to be significant since the ion microprobe analyses of both the as-received and hydrogenated standards were quite accurate and reproducible.

\section{Laser Microprobe}

Standards. - Portions of the same two standards that were used for the ion microprobe analyses were also used to determine the characteristics and accuracy of the laser microprobe technique. As discussed earlier, the laser microprobe technique requires analyses at multiple locations on a sample cross section to develop a concentration profile. 


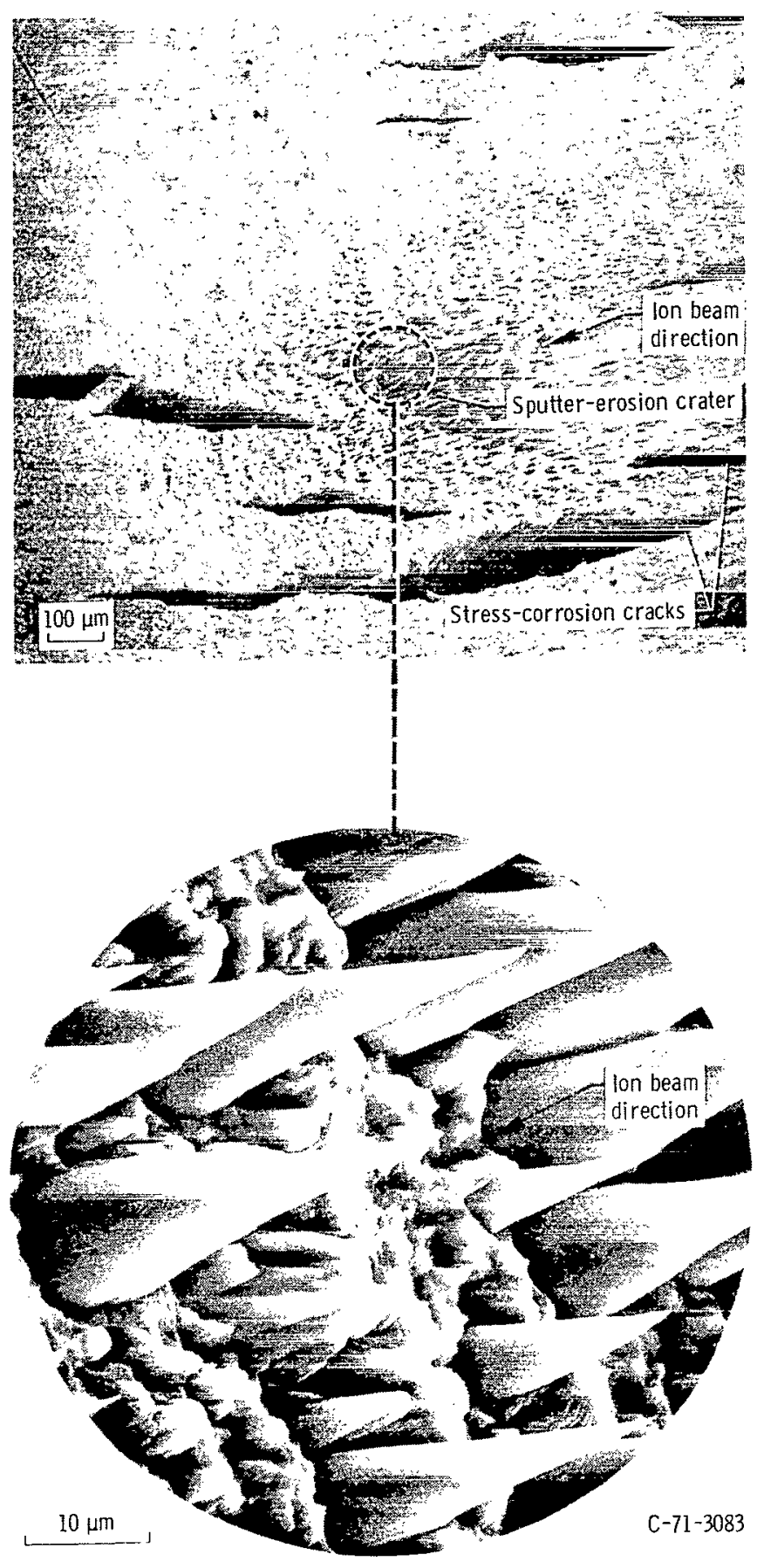

Figure 9. - Scanning electron micrographs of ion microprobe sputter-erosion crater (profile 2 of fig. 8). 
The hydrogen concentration profiles for the as-received alloy bar stock and the thermally hydrogenated specimen are presented in figure 10. The analyses of the bar stock decreased from $68 \mathrm{ppm}$ below the surface of the wafer to $14 \mathrm{ppm}$ at a depth of 800 micrometers. This apparent concentration gradient may be an artifact due to the closeness of adjacent analysis sites and is not related to the gradients observed in the as-received standard with the ion microprobe technique. The depth of the initial laser microprobe analysis is about 200 micrometers below the surface; the gradient observed with the ion microprobe had disappeared at about 100 micrometers below the surface. A remote site was analyzed with the laser microprobe and found to contain $65 \mathrm{ppm}$ hydrogen, which agrees quite well with the as-received standard of $70 \mathrm{ppm}$ hydrogen. Therefore, it appears that some depletion of hydrogen from areas adjacent to the heat affected zone may occur. For improved accuracy, the analysis sites probably should have been more widely spaced.

The analyses for the thermally hydrogenated specimen agreed well with the vacuum fusion value of $3800 \mathrm{ppm}$. The measured concentrations ranged from 1800 to $4300 \mathrm{ppm}$ across the entire thickness of the tubular specimen.

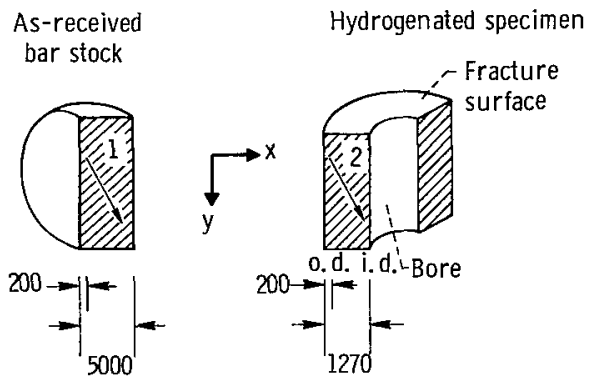

All dimensions in $\mu \mathrm{m}$

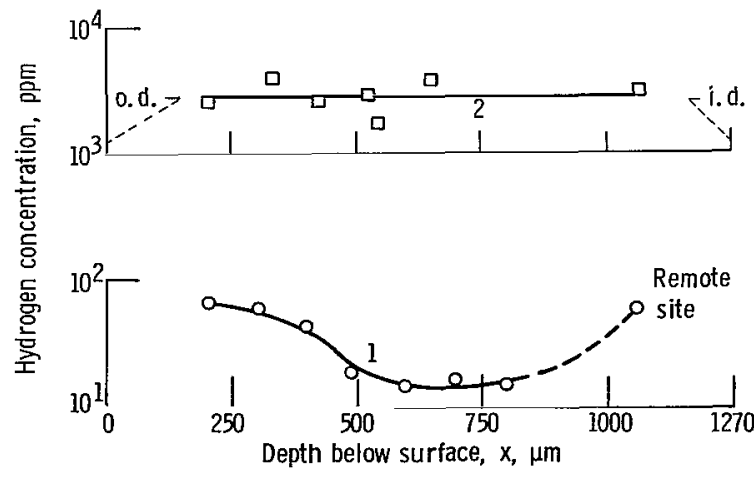

Figure 10. - Laser microprobe hydrogen concentration profiles for as-received standard $(70 \mathrm{ppm} \mathrm{H})$ and thermally hydrogenated specimen $(3800 \mathrm{ppm} \mathrm{H})$. (The arrows in the sketches indicate the path of analysis sites from the in itial to the final locationl. 
Stress-rupture specimen. - A portion of the same stress-rupture specimen analyzed with the ion microprobe was also analyzed with the laser microprobe. The locations of the three profiles are shown in figure 11. For profiles 1 and 3 , the y coordinate increased a constant 317 micrometers between analysis sites. For profile 2, the distances between the three locations selected for analysis was 75 and 100 micrometers along the y coordinate.

Profiles 1 and 2 were both initiated close to the intersection of the stress-corroded bore and the fracture surface. Hydrogen concentrations for profile 1 decreased from 3700 to $90 \mathrm{ppm}$ and then increased to $1400 \mathrm{ppm}$ on a traverse along the length of the specimen. It is possible that the value of $1400 \mathrm{ppm}$ hydrogen represents the local concentration of hydrogen near a deep stress-corrosion crack parallel to but some distance from those cracks observed on the fracture surface. The hydrogen concentrations measured along profile 2 decreased from the initial value of $3700 \mathrm{ppm}$ to 400 and $540 \mathrm{ppm}$ as the traverse approached the intersection of the fracture surface and the outer diameter of the specimen. Profile 3 was initiated between the outer and inner diameters of the specimen. Hydrogen concentrations increased from 700 to 4400 ppm as the analysis sites approached the intersection of the corroded and fracture surfaces.

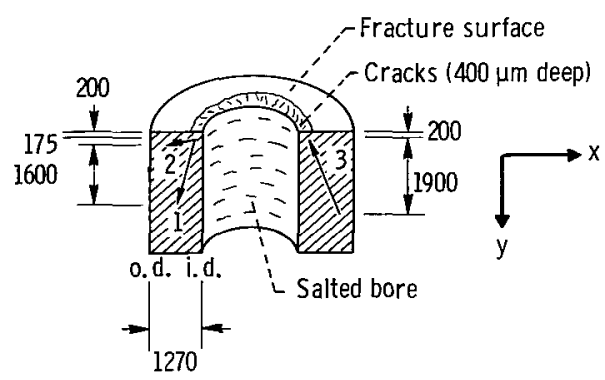

All dimension in $\mu \mathrm{m}$

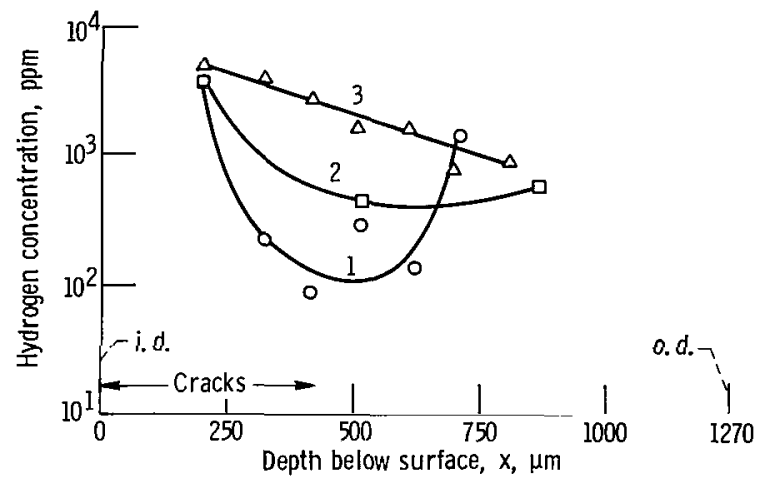

Figure 11. - Laser microprobe hydrogen concentration profiles for stress-rupture specimen. (The arrows in the sketch indicate the path of analysis sites from the initial to the final location). 


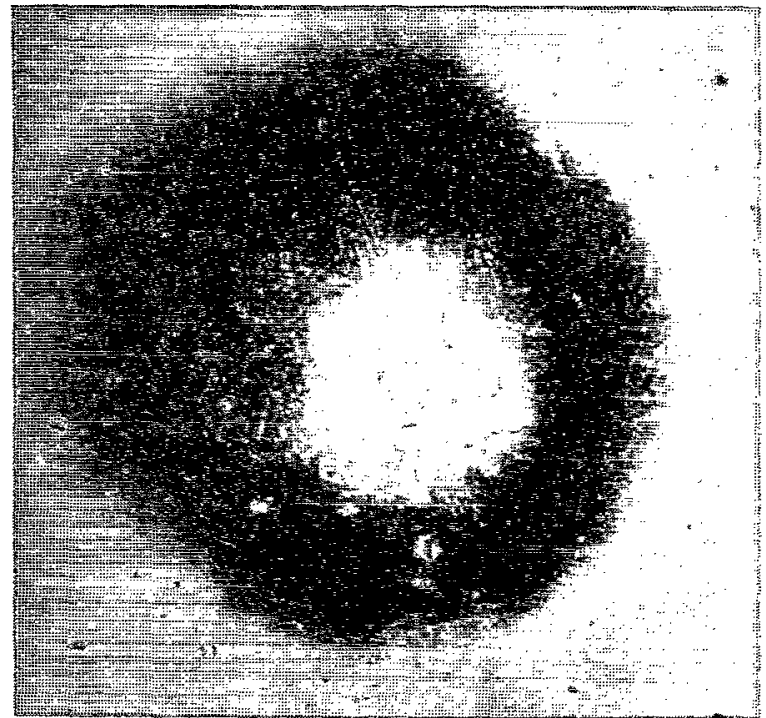

(a) Typical surface view.

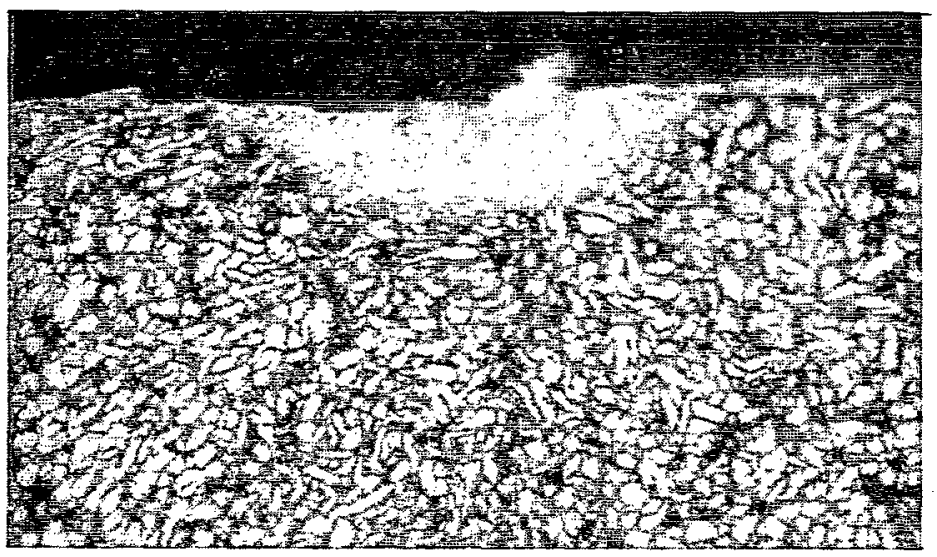

(b) Location 2 (60 ppm H).

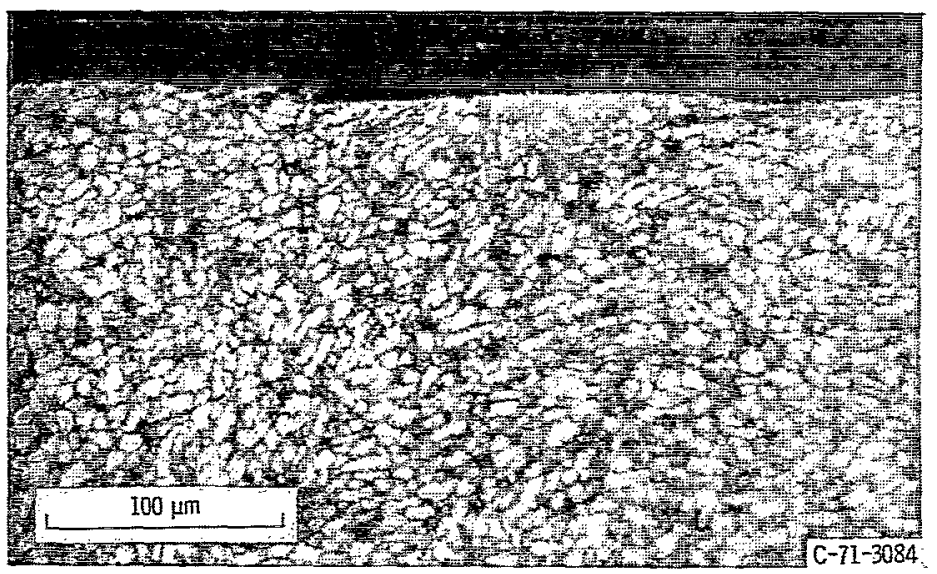

(c) Location 5 (14 ppm H).

Figure 12. - Metallographic examination of laser microprobe heat affected zones of asreceived standard $(70 \mathrm{ppm} \mathrm{H}$ ) (exposed 30 seconds at 30 watts). 
These profiles indicate substantial quantities of corrosion-produced hydrogen near the intersection of the stress-corroded bore and fracture surface of the specimen. The levels of hydrogen measured were commonly several thousand ppm. Remarkable agreement was observed for these laser microprobe analyses between traverses starting near either the inner (profile 1) or outer (profile 3) diameter of the specimen. The quantitative analyses of hydrogen concentrations near the fracture surface determined by both the ion and laser microprobes were also in excellent agreement with each other.

Metallography. - The heat affected zone (HAZ) of each laser microprobe analysis site on the as-received bar stock standard was examined metallographically at $\times 250$. Both surface and section micrographs were made for all analysis locations. Some representative photomicrographs are shown in figure 12. A surface view of the $\mathrm{HAZ}$ (fig. 12(a)) shows that its diameter is about 250 micrometers. The corresponding transverse section shown in figure $12(\mathrm{~b})$ also indicates that the diameter of the HAZ is about $250 \mathrm{mi}-$ crometers, but it is not quite the hemispherical shape that has been assumed for all hydrogen concentration calculations. The hydrogen concentration from this location was $60 \mathrm{ppm}$ (see fig. 10; depth, $300 \mu \mathrm{m}$ ). The HAZ for a location that was analyzed to contain $14 \mathrm{ppm}$ is shown in figure 12(c) (see fig. 10; depth, $600 \mu \mathrm{m}$ ).

Since none of the HAZ are truely hemispherical in shape and few of them are as deep as had been assumed, the actual mass of alloy from which hydrogen was liberated was usually less than the assumed mass $(10 \mu \mathrm{g})$. Hence, the concentrations of hydrogen that were calculated from the baseline assumptions represent values somewhat less than the true hydrogen concentration of the HAZ. Therefore, it is reasonable to assume that many of the hydrogen concentration levels are actually greater than those presented in figures 10 and 11.

\section{GENERAL REMARKS}

The limited microanalytical data determined in this investigation confirm that corrosion-produced hydrogen is concentrated to extremely high levels near the intersection of the corroded and fracture surfaces. High hydrogen concentrations were also measured slightly below the fracture surface of a creep-exposed specimen that did not have any evidence of stress-corrosion cracks. These microanalyses demonstrate that local concentrations of hydrogen may be as much as several orders of magnitude greater than the average values determined by bulk chemical analyses. This supports the previously proposed concept that corrosion-produced hydrogen is responsible for the embrittlement and cracking observed during hot-salt stress-corrosion exposures. 
It is obvious from the results presented in this report that additional research is necessary to determine completely and more accurately the distribution of hydrogen in stress-corroded specimens. For example, a contour map of hydrogen content could be determined if many additional profiles were made. To clearly indicate the distribution of hydrogen, these profiles should be close to each other and should extend from shallow depths of less than 0.1 micrometer to several hundred micrometers below saltcorroded and fracture surfaces.

Similar information regarding local segregation and distribution of hydrogen would be immensely valuable in many other areas of corrosion, stress-corrosion, and hydrogen embrittlement research. Corrosion-produced hydrogen has long been suspected as being the embrittling species in many stress-corrosion systems. Hydrogen is known to be the embrittling species generated during the electroplating of high-strength steels.

One well known theory (ref. 3) has suggested that hydrogen segregates to crack tips and to the roots of notches. Other theories postulate that hydrogen adsorbed on surfaces is responsible for embrittlement. However, there had been no quantitative analytical techniques capable of measuring hydrogen concentrations on a microscopic scale and thereby supporting either of these opposing theories of hydrogen embrittlement. The techniques used in this investigation offer the distinct possibility of actually determining complete contour maps of hydrogen content beneath corroded and fracture surfaces.

These techniques, or modified versions of them, may also be useful for numerous aerospace, chemical, and marine applications. They could be used to study gaseous hydrogen embrittlement and welding contamination and for quality control during electroplating processes. It appears that the laser microprobe is particularly suited for field inspection of potential stress-corrosion problems.

Obviously, much additional research is required to fully define the capabilities and accuracie 3 of these techniques. Some of the deficiencies discussed previously as well as some advantages will be summarized in the following sections.

\section{Ion Microprobe}

As demonstrated by the experimental conditions used in this investigation, it is apparent that a continuous concentration profile can be generated from one analysis location. Since no sectioning is required, the analysis can be considered to be essentially nondestructive provided the analysis crater is small with respect to the size of the sample or piece of hardware.

This technique also has the potential for quantitative near-surface analyses. This investigation demonstrated that analyses could be initiated at depths of 0.1 micrometer. 
It is probable that analyses could be made at depths of about 0.01 micrometer or less if a defocused beam and/or lower sputtering rates were used.

There is no risk of specimen contamination since both as-corroded and as-fractured surfaces can be examined and analyzed without requiring any cleaning, cutting, mounting, polishing, or etching operations. This and other variations of the ion microprobe are currently available from several firms. It is possible that additional development would result in better resolution, a smaller beam size, and a portable system suited for field inspection.

The scanning electron microscope examinations revealed some problems that need to be resolved. For the experimental conditions used in this investigation, the following observations were made: (1) Crater depths were up to 50 percent shallower than the depths calculated from sputtering rates; and (2) crater morphology was far from a smooth, Gaussian type. These problems became accentuated as sputter-erosion times increased.

\section{Laser Microprobe}

Additional development of the laser microprobe could result in a pulsed laser with a higher intensity and smaller beam diameter. Such a beam would reduce both the diameter and depth of the heat affected zone, which would permit analyses in a manner similar to the ion microprobe technique. Specifically, near surface analyses could be determined, concentration profiles might be developed from a single analysis site, and an essentially nondestructive technique could result. The concurrent decrease in the volume of hydrogen liberated from the smaller microsample would necessitate the development of a more sensitive hydrogen detector or possibly the inclusion of a mass spectrometer in the analytical end of the system.

It would be desirable to include an optical system so that the sample could be accurately positioned for the initial analysis. The present technique appears to be quite sensitive to sample size and sample surface orientation with respect to the incoming beam. The present mode of operation involves the destruction of the sample or piece of hardware to obtain the necessary cross-sectional sample for three-dimensional analysis. Thus, there is the attendant risk of altering the hydrogen distribution or even contaminating the sample during sectioning.

Metallographic examination revealed several problems that must be considered. For the experimental conditions used in this investigation, the following observations were made: (1) The HAZ may be smaller and less hemispherical than assumed; (2) for a presumably constant laser power level and exposure time, neither the diameter nor 
the depth of the HAZ are as reproducible as desired; (3) the HAZ appears to be quite sensitive to the initial surface condition of the sample and the proximity of adjacent HAZ.

\section{SUMMARY OF RESULTS}

Two advanced analytical techniques were used to quantitatively measure hydrogen concentrations on a microscopic scale in a titanium alloy. Baseline characteristics of both the ion microprobe and the laser microprobe techniques were determined by analyzing standards of the Ti-8Al-1Mo-1V alloy with known levels of hydrogen. Samples of the same alloy that had been subjected to various hot-salt stress-corrosion exposures were then analyzed in stepped intervals below both corroded and fracture surfaces for hydrogen content.

1. Concentrations of several thousand ppm hydrogen were measured below the fracture and stress-corroded surfaces of specimens in areas either 22 or 300 micrometers in diameter. These extremely high concentrations of corrosion-produced hydrogen support a previously proposed concept that hydrogen is the embrittling species in the process of hot-salt stress-corrosion of titanium alloys.

2. The results obtained with both the ion and laser microprobe techniques were in excellent agreement with each other. Concentrations of hydrogen decreased from several thousand ppm to the base-alloy level as the depth below fracture and corroded surfaces increased from a few micrometers to several hundred micrometers.

3 . High hydrogen concentration gradients were measured close to the fracture surface. Profiles initiated parallel to but far away from the fracture surface showed a constant baseline hydrogen level.

Lewis Research Center,

National Aeronautics and Space Administration, Cleveland, Ohio, September 29, 1971, 134-03.

\section{REFERENCES}

1. Gray, Hugh R.; and Troiano, Alexander R.: How Hydrogen Affects Maraging Steel. Metal Progress, vol. 85, no. 4, April 1964, pp. 75-78.

2. Farrell, K.; and Quarrell, A. G.: Hydrogen Embrittlement of an Ultra-HighTensile Steel. Jr. Iron and Steel Inst., vol. 202, no. 12, Dec. 1964, pp. 10021011. 
3. Troiano, Alexander R.: The Role of Hydrogen and Other Interstitials in the Mechanical Behavior of Metals. Trans. Amer. Soc. Metals, vol. 52, 1960, pp. 54-80.

4. Rideout, S. P.; Louthan, M. R., Jr.; and Selby, C. L.: Basic Mechanisms of Stress-Corrosion Cracking of Titanium. In Stress-Corrosion Cracking of Titanium, Spec. Tech. Publ. No. 397, ASTM, 1966, pp. 137-151.

5. Gilpin, C. B.; Paul, D. H. ; Asunmaa, S. K. ; and Tiner, N. A. : Electron Microautoradiography and Its Application to the Study of Hydrogen Distribution in Steel. In Advances in Electron Metallography, Vol. 6, Spec. Tech. Publ. No. 396, ASTM, 1966, pp. 7-20.

6. Wilson, Charles R.: Neutron Radiography Complements X-Ray. Metal Progress, vol. 98, no. 2, Aug. 1970, pp. 75-76.

7. Hagemaier, D.; Halchak, J.; and Basl, G.: Detection of Titanium Eydride by Neutron Radiography. Materials Evaluation, vol. 27, no. 9, Sept. 1969, pp. 193-198.

8. Padawer, Gerald M.; and Schneid, Edward J.: The Lithium Microprobe as a Tool for Hydrogen Microanalysis at Surfaces. RM-467J, Grumman Aircraft Eng. Corp., Dec. 1969.

9. Toy, S. M.; and Phillips, A.: Hydrogen Emanation and Distribution in Metals and Alloys. Corrosion, vol. 26, no. 7, July 1970, pp. 200-207.

10. Gray, H. R.: Role of Hydrogen in Hot-Salt Stress-Corrosion of a Titanium Alloy. NASA TN D-6188, 1971.

11. Gray, H. R.: Hot-Salt Stress-Corrosion of Titanium Alloys: Generation of Hydrogen and Its Embrittling Effect. Corrosion, vol. 25, no. 8, Aug. 1969, pp. $337-341$.

12. Gray, Hugh R.; and Johnston, James R.: Hot-Salt Stress-Corrosion of a Titanium Alloy in a Dynamic Air Environment. Metallurgical Trans., vol. 1, no. 11, Nov. 1970, pp. 3101-3105.

13. Herzog, R. F. K.; Poschenreider, W. P.; and Satkiewicz, F. G.: Mass Spectrometer Analysis of Solid Materials with the Ion-Microprobe Sputter Source. NASA CR-683, 1967.

14. Westerman, E. J.: The Ion Microprobe Mass Spectrometer in Aluminum Alloy Research. Jr. of Metals, vol. 22, no. 12, Dec. 1970, pp. 28-31.

15. Blickwede, Donald J.: The Importance of Surface Composition. Metal Progress, vol. 96 , no. 5, Oct. 1969 , pp. 77-80. 
16. Korasek, F. W.: The Ion Microanalyzer. Research/Development, vol. 21, no. 2, Feb. 1970, pp. 32 and 100.

17. Caves, Robert M. ; and Grisaffe, S. J.: Electron and Ion Microprobes Applied to Characterize an Aluminide Coating on IN-100. NASA TN D-6317, 1971.

18. Lieble, Helmut: Ion Microprobe Mass Analyzer. J. Appl. Phys., vol. 38, no. 13, Dec. 1967, pp. 5277-5283.

19. Nixon, W. C.: Scanning Electron Microscopy. Contemporary Physics, vol. 10, no. 1, Jan. 1969, pp. 71-96. 
NATIONAL AERONAUTICS AND SPACE ADMISTRATION

WASHINGTON, D.C. 20546

OFFICIAL BUSINESS

PENALTY FOR PRIVATE USE \$300

FIRST CLASS MAIL

POSTAGE AND FEES PAID NATIONAL AERONAUTICS AND SPACE ADMINISTRATION

\author{
107001 C1 U 17 711203 S00903DS \\ IEPT OF THE AIR FORCE \\ F WEAPONS LAB (AFSC) \\ 'ECH LIBRARY/WLOL/ \\ TTN: E LOU BOWMAN, CHIEF \\ IRTLAND AFB NM 87117
}

$\begin{array}{ll}\text { POSTMASTER: } & \text { If Undeliverable (Section } 158 \\ \text { Postal Manual) Do Not Return }\end{array}$

"The aeronautical and space activities of the United States shall be conducted so as to contribute . . to the expansion of buman knowledge of phenomena in the atmosphere and space. The Administration shall provide for the widest practicable and appropriate dissemination of information concerning its activities and the results thereof."

- National Aeronautics ANd SPACE ACt OF 1958

\title{
NASA SCIENTIFIC AND TECHNICAL PUBLICATIONS
}

TECHNICAL REPORTS: Scientific and technical information considered important, complete, and a lasting contribution to existing knowledge.

TECHNICAL NOTES: Information less broad in scope but nevertheless of importance as a contribution to existing knowledge.

TECHNICAL MEMORANDUMS:

Information receiving limited distribution because of preliminary data, security classification, or other reasons.

CONTRACTOR REPORTS: Scientific and technical information generated under a NASA contract or grant and considered an important contribution to existing knowledge.
TECHNICAL TRANSLATIONS: Information published in a foreign language considered to merit NASA distribution in English.

SPECIAL PUBLICATIONS: Information derived from or of value to NASA activities. Publications include conference proceedings, monographs, data compilations, handbooks, sourcebooks, and special bibliographies.

\section{TECHNOLOGY UTILIZATION} PUBLICATIONS: Information on technology used by NASA that may be of particular interest in commercial and other non-aerospace applications. Publications include Tech Briefs, Technology Utilization Reports and

Technology Surveys.

Details on the availability of these publications may be obtained from:

SCIENTIFIC AND TECHNICAL INFORMATION OFFICE

NATIONAL AERONAUTICS AND SPACE ADMINISTRATION

Washington, D.C. 20546 